\title{
Meeting Josh Groban (Again): Fan/Celebrity Contact as Ordinary Behavior
}

\author{
Gayle Stever \\ Empire State College, Rochester, NY \\ gayle.Stever@esc.edu
}

\begin{abstract}
In a participant-observer ethnographic study, the researcher offers evidence from 10 years of observation of the Josh Groban fandom as an example of fans becoming friendly acquaintances of celebrities. Contrary to the way much of the psychological literature depicts fans, as celebrity worshippers or stalkers, the largest percentage of the fans observed in this study showed normal social engagement with others outside of their fan activity, and a friendly acquaintanceship with Groban that is similar to other kinds of relationships happening outside of the context of mediated relationships. Fans who pursued these relationships did so within a social context and network of other fans in most cases. Connection through music, relief from various kinds of life stressors, or the desire to participate in charity efforts are offered as some of the explanations for what motivates the fan to seek out this kind of relationship with an attractive media persona.
\end{abstract}

KEYWORDS: fan, celebrity, parasocial, ethnography, audience

\section{Introduction}

Social relationships are defined within a culture in a myriad of ways. While more traditional relationships have been the focus of much social psychological research, little has been done to try to define the face-to-face social relationships that develop between a media celebrity and his or her fans. These relationships exist, they can be significant in the lives of both celebrities and fans, and they are a normal occurrence for a media-saturated society. 
This trend to overlook the ongoing relationships that fans have with celebrities is part of what has been referred to as the "marginalization of celebrity" (Duffett 2014: 163). Often when this topic is engaged in the literature, the idea that a fan can meet or know a celebrity is treated as fantastic and unrealistic (Leets et al. 1995). Duffett points out that the fan/celebrity relationship has either been pathologized or has been removed from the fan studies equation altogether (Duffett 2014; Jenkins 1992).

The specific goal of this paper is to describe a case study of a single artist fan phenomenon observed over a period of more than 10 years, as an example of the relationship that develops between individual fans and celebrities who have organized fandoms with which they have regular contact. While this has been observed with at least 20 different celebrities over a period of 28 years, this paper focuses on the case of Josh Groban and his fans.

\section{Literature}

Previous studies have discussed the motivations for forming a relationship with a celebrity, including task attraction ("this person is the best at I have ever seen"), romantic attraction ("this person is attractive and appealing to me in a romantic way"), and attraction based on the character and qualities of the person ("this person is a good person, a role model to me, and someone I want to be like"; Rubin and McHugh 1987; Stever 2009a, 2011a). Attraction to the familiar faces and voices of others in all contexts is a characteristic of human beings from an evolutionary perspective, with the human predisposition to attraction being "hard-wired" into the DNA and brain structure of the individual. Media makes the images and voices of celebrities very familiar, and the tendency to form attachments easily follows (Stever 2016).

Much academic literature on the subject of celebrity focuses on the remoteness of the celebrity. In most cases the celebrity is only known through media and the connection is parasocial (Giles 2010; Hartmann and Goldhoorn 2011; Horton and Wohl, 1956; Klimmt et al. 2006; Stever 2009b, 2011b, 2013), a relationship where the celebrity has not reciprocated the relationship with the fan in any way and fan is completely unknown to the celebrity.

Studies that have described reciprocated personal fan/celebrity encounters (Bennett 2014; Cavicchi 1998; Click et al. 2013; Dilling-Hansen 2015; Reijnders et al. 2014; Stever and Lawson 2013) have focused on either single meetings that are "one of a kind" or reciprocated encounters through social media.

An exception to this would be Zubernis and Larsen's (2012) description of the fandom for the television program, Supernatural. The emphasis in their discussion is on fan interaction with creative production team members, people within the world of fandom who qualify as celebrities. While no scholarly articles to date have been written about individual fans and their relationships with Peter Jackson, the producer and director of the Lord of the Rings films, the web site, The One Ring.net, known in fandom as TORN, represents an ongoing relationship between Lord of the Rings luminaries and fans wherein fans gained unusual access to the sets and producers of those movies. In another case, Joss Whedon, creator and producer of shows like Buffy the Vampire Slayer has an interactive relationship 
with the fans of his shows (Mittell 2006). The work in this area has been done to a large extent outside of music fandom, at least so far as the scholarly literature is concerned. Anecdotal popular accounts like Pamela Des Barres' I'm With the Band: Confessions of a Groupie are plentiful but lack theoretical focus (Des Barres and Navarro 2005).

In this paper, the focus is on relationships between fans and celebrities that are social, not parasocial. In fan groups studied by this researcher beginning with Michael Jackson in 1988 up until the present, there were subsets of fans who had face-to-face relationships with celebrities, who were known and had relationships that appeared to have meaningfulness on both sides of the relationship.

Some literature has focused on fans of this type who show pathological signs of celebrity worship, stalking and other such behaviors (Maltby et al. 2006; McCutcheon et al. 2003; McCutcheon et al. 2016). The fan as "stalker" is an almost iconic symbol in media (Duffett 2013), fed by popular films such as Play Misty for Me as well as real-life incidents like the murder of John Lennon by Mark David Chapman or the more recent murder of The Voice star, Christina Grimmie, by Kevin Loibl. Studies have been devoted to the stalker (Ferris 2001, 2004, 2005) but the vast majority of people who participate in any media fandom do not match this profile. One important distinction is to separate ordinary approach behavior from invasive staking behavior. Merriam-Webster (2004) has defined stalking as "to follow, watch, and bother (someone) constantly in a way that is frightening, dangerous, etc." By this definition, going to concerts, plays, conventions or other public events for which a ticket has been purchased or to which the public is invited and where no threatening approach has been made cannot be considered stalking in any context. "Some psychologists remain certain that extreme fandom is potentially dangerous, because fixated fans who are ignored by their heroes are predicted to react angrily" (Duffett 2013: 93). If such predictions were true, then it would follow that fans who are not ignored would be less likely to act out against their favorite celebrity.

Thorne did a qualitative study looking at fan behavior, providing validity and support for a four level model of fandom that included "Dilettante", "Dedicated", "Devoted" and "Dysfunctional" fans. Only fans in the Dysfunctional category exhibited behavior that "violated social norms" (2011: 162) including stalking behavior. The results revealed that stalking and other extreme behaviors were only exhibited by a minute percentage of the fans in the study, a finding that mirrors the percentage of "borderline pathological fans" $(3 \%)$ in the celebrity worship studies (Maltby et al. 2006; Stever 2011a).

The present finding is that while things like stalking and celebrity worship do exist, indeed are somewhat frequent, there is a much larger subset of fans that have real and positive relationships with their favorite celebrity, and are reciprocated on some level by the celebrity. This part of organized fandom has been largely ignored, in particular, by the psychological and sociological literature on fandom. 


\section{Methods}

Participant observer ethnography is defined as

a family of methods involving direct and sustained social contact with agents, and of richly writing up the encounter, respecting, recording, representing at least partly in its own terms, the irreducibility of human experience. Ethnography is the disciplined and deliberate witness-cum-recording of human events. (Willis and Trondman 2000: 5)

It is also differentiated from traditional empirical research in that it has

a strong emphasis on exploring the nature of particular social phenomena, rather than setting out to test hypotheses about them, with a tendency to work primarily with "unstructured" data, that is, data that have not been coded at the point of data collection in terms of a closed set of analytic categories. (Atkinson and Hammersley 1994: 248).

Charmaz has defined Grounded Theory analysis as an emergent method that "builds an inductive understanding of (the world) as events unfold and knowledge accrues" (2008: 155).

The current study has employed, over a period of 10 years, an inductive, grounded theory method employing participant observer ethnographic analysis of a case study of a popular music fandom. Rather than beginning with specific hypotheses, the work sought to understand the phenomenon as a case study of a music fandom, allowing hypotheses and themes to emerge from data and observations. The emphasis from the beginning has been to gather information, both qualitative and quantitative, in order to gain a broad and deep understanding of what drives each fan to participate in a prolonged and committed way.

Groban was chosen because he had, by 2005, a large and growing music fandom. His record sales, his sold out tours, and the size of his online fan club made this an attractive case study for trying to understand what drives popular music fandom in a postmodern and largely Internet driven world. The researcher looked at this fandom as a possible case study in 2005 after attending a concert on the Josh Groban: Closer tour (2003 to 2005). Having been taken to the concert by a friend who was familiar with the researcher's work and its parameters, the researcher observed many elements that defined this as a large international fandom committed in a personal way to Groban.

This study was conducted in the context of earlier data collection and observation within fandoms for Michael Jackson, Bruce Springsteen, Madonna, Prince, Janet Jackson, Paul McCartney, Star Trek, and a number of other international media fandoms.

While some fan studies of this type have been done by "Aca-fans" ${ }^{1}$ or selfidentified fan/academics who were already fans of the studied phenomenon, this researcher knew next to nothing about Josh Groban and had no participation in either organized or less formal fan groups. At the first concert in 2005, the researcher was hearing most of the music for the first time (excepting a few songs on the radio). A discussion of why this might be important is outside the scope of this article, but the information is provided to put the study into context as the 
pursuit of understanding something from an outsider perspective by trying to gain the perspective of an insider. The researcher tried to do everything fans do (in this and other studied fandoms), but does not qualify as the more serious kind of fan in the study (evidenced, in part, by how easy it has been to move on after each study). "Interpretivists believe that reality is not objectively determined but is socially constructed" (Kelliher 2005: 123). To make clear to the reader the context of a study, one must define the lens of the interpreter and this paragraph is offered in pursuit of that goal.

The researcher joined Groban's official fan club and began to network among fans, identifying herself as a fan studies researcher. She traveled to Los Angeles to an organized fan event, a charity event benefitting Groban's high school, the Los Angeles County High School for the Arts (LACHSA). This was the first event, in August, 2006, where the researcher actually met Groban, at an event with about 110 attendees, and also began to meet fans from around the United States. In the months before this meeting, the researcher had travelled to Los Angeles to attend a smaller charity event to benefit a student at LACHSA whose parents had been killed in an auto accident. Groban's fan charity organization, Grobanites for Charity (GFC), were raising money to help the family after this tragedy, and it was at this smaller event (May 2006) that the GFC volunteers were first encountered and interviewed with respect to their activity. At least a dozen individuals active in the charity were interviewed both at the beginning of the study and during the intervening years since.

In 2007, Groban began a tour to support his album, Awake, and the researcher began - with the first concert in February, 2007 - to attend as many concerts as possible, both in the US but also in Canada and Europe, attending 30 concerts and their connected charity events (usually dinners before the concerts). At each charity event, questionnaire data was gathered (Stever 2008, 2011a) and less formal brief interviews were conducted. After many of the concerts Groban was observed interacting with fans. Further tours were used to follow up on this early data, with multiple dates attended on the four tours from 2010 to 2016. Single events like Chess: The Musical in London in May 2008 were also attended.

About 200 fans were interviewed at the early stage (2007) of the research (about 6-7 per concert) and notes kept from these interviews. Survey data of over 600 questionnaires; both the Celebrity Appeal Questionnaire (Stever 2008) and the Celebrity Attitude Scale (Maltby et al. 2006) were given. In addition, the researcher attended charity drives, television tapings, and other fan related events. She participated on an ongoing basis on the fan club web site, and later on various fan pages on Facebook. Groban was observed interacting with individual fans on at least 100 occasions over this 10 year period.

Singer/actor/composer Josh Groban has sold over 30 million albums, and has been on national television on sitcoms like Ally McBeal and The Office, and shows like Dancing with the Stars and CSI. He hosted the reality singing show Rising Star, and has sung for the Grammys, The Tony's, and The US Open... plus an almost unending list of high profile media events including the 2002 Winter Olympics, seen by an estimated 4 billion people. At the time of the current discussion (2016), he is 35 years old. He has been a public figure with an active fan following since 2001. 
Many of the fans interviewed for this study had been his fans since the beginning of his career. Others joined later. Most participants lived in the United States, Canada, France, the United Kingdom, Germany, the Netherlands and other countries in Europe. The researcher has traveled to Canada, France, the United Kingdom, Germany and the Netherlands, some of these places multiple times. The findings for this study are a synthesis of the coding of field notes and interviews. Field notes were kept principally on secured Microsoft Word files, and codes and research memos kept on auxiliary Word files. Summary analyses at regular intervals have been published over the years that the work was done (see Stever 2008, 2009a, 2011a, 2011b, 2011c, 2013, 2016). Questionnaire data has been kept in secured files and those analyses published as already noted.

Not all celebrities have an interest in forging a connection with fans (Kanye West and Kim Kardashian are notable examples). In contrast, Groban and his fans are the focus of this paper because they have exhibited qualities that make this a relevant case study when trying to understand the development of fan/celebrity relationships.

\section{Findings}

When the work of investigating fan-celebrity interaction began in 1988, this researcher was not anticipating what was observed. The media depiction of these relationships being distant and parasocial seemed reasonable. It was from closer observation over a period of years that it became clear that social real-life relationships are common, normative, and largely invisible to outsiders because the very nature of the literature on fandom (focusing on things like "worship" and "stalking") makes the veteran fan wary of letting outsiders know that he or she has what could be described as a friendly acquaintanceship with the celebrity. This observation was drawn from interviews with fans from a variety of groups including this one.

The term "friendly acquaintanceship" is used to describe the relationship between, in this case, Groban and his fans, because it seems the most appropriate way to describe the interactions observed. In all but the rarest of cases, the word "friend" would not apply as friendship presumes equitable interaction and access. But an acquaintance is known and recognized. Merriam-Webster (2004) defines an acquaintance as "a person whom one knows but who is not a particularly close friend".

The following quotes have been taken from the website ThatJoshGrobanGuy.com and reflect things Groban has said about his fans over the years. Note that the first quotes speak to the overall positive tone of the relationship, and are followed by quotes where Groban acknowledged his connection to very specific individual fans.

They are a very dedicated, very loyal, very energetic group of fans ... and they're the best, and they're mine, and I'm theirs. (CBC Canada 2003) 
To the untrained eye they're ecstatic fans who wear lots of pins and "Josh" tshirts and make signs and drawings. But deep down they're much more ... It's a great feeling to have so many great people supporting you. (VH1 2003)

About specific individual fans: ET Canada afforded the fans a chance to Tweet questions and some were selected for a live interview on their program. This exchange was part of that program in 2015 (ET Canada Global TV 2015).

SYMPHANIE [Twitter handle]: You know certain fans from certain cities. Do you ever look at the regulars and think "Oh you again..." or do you just love us?

GROBAN: Symphanie is one I see at every show. I know exactly who she is. She was just there this morning when we were taping the show. Yes it's funny she would ask that question because there are ... you can be in an arena of 15,000 people and the two front rows are the same people every single night. It's incredible. I don't know how they can afford to go to all the shows, but thank you for coming!

In 2004, Groban began to build a fan base in the United Kingdom but it was slow going at first. On June 27, 2008, he sang at the 90th birthday celebration for Nelson Mandela which was in Hyde Park in London. A few days later, in a video blog posted on his fan club web site he said:

I saw a few of you actually in the front row which is saying something because there were 46,664 people there and so when I came out and saw some fans that I recognized yelling and screaming in the front row, that made me feel great because in the UK we still have a lot of work to do. Thanks for coming out and showing that support.

Again on November 24, 2010, at the Union Chapel concert in London (recorded on YouTube) a fan who was well known to him raised her hand during the question and answer part of the concert. He called on her and said "You are at every single show, bless your heart. You're at every TV show and at every concert, and you're the best. Thank you very much!" Later on June 21, 2013 at the Glasgow Royal Concert Hall, he recognized the same fan, saying, "I have a fan from England who has the greatest laugh I've ever heard in my life and I feel like something is missing if I don't hear her laugh at some point during a show".

Then on September 8, 2013, just after another large Hyde Park concert, he Tweeted to the UK fans: "Big shout out to the fans who had a banner in the front for me. You made me feel at home".

One of the members of the fan club lived close enough to Los Angeles to go to all of the tapings of Live with Jimmy Kimmel when Groban appeared, and he often came out to sign autographs afterwards. On the January 4, 2011, Groban stopped in front of her to say:

I think you get an award for the most Tweets. [He high fives her]. You're MAF... yeah you are on there 24/7. [She replied: I hope that's OK]. No are you kidding? I'm like God Bless Her! I Love it! I wanted to give you a high five for that. That's a lot of dedication. Thank you. 
Then again on February 13, 2013, after Jimmy Kimmel, he said to the same fan "You are the queen of Twitter. Do you ever sleep? Thank you for all you do". These conversations are recorded on YouTube, taped by a web show called popCandies and during the same sessions you can see Groban, a number of times, saying, "Hello it's good to see you again", as he greets fans with varying levels of familiarity as he clearly sees familiar faces.

On many other occasions, Groban was observed to recognize individual fans, greet them, often by name, and recount an earlier conversation or other shared encounter. The half a dozen fans noted above are only a small number of the fans that I personally saw Groban recognize and acknowledge, often remembering them by either name or Twitter handle. Of the one hundred plus occasions where Groban was observed interacting with fans, on such occasions there were anywhere from five to fifteen individual fans being acknowledged and recognized in various social settings.

A common situation reported in interviews was the fear of being perceived as a "stalker" for attending repeat events, with fans recounting that after telling someone they are attending four or more concerts on part of a tour, the joking (or not so joking) response might be "Does he know you are stalking him?" In various discussions about and with fans, there were people who reacted as if attending multiple concerts on the Groban tour was odd, but also indicated that they think there is nothing at all wrong with attending, for example, all of the games in a season of football for the same team. It would be rare to be accused of "stalking" a football team if one had season tickets. Data on this is limited at this time, but it came up in enough coded fan interviews and also discussions with family members of fans that it is an issue worth exploring in future research, that is, a comparison of the perception of sports fans vs. media celebrity fans.

\section{Places for Interaction}

In order for a social connection to be forged with a celebrity, there have to be opportunities for interaction. A single meeting is not enough to forge a friendly acquaintanceship. The fans observed who were known by Groban had usually met him over a period of years in a multiplicity of social situations. In some cases, the foundation for the relationships was formed early in Groban's career when he was still a relative unknown. But other fans came into the fandom more recently and still have forged a connection that makes them familiar and recognized at encounters. Not all fans known to a celebrity are known by name. Some are just a familiar face encountered repeatedly over a series of events. Others, for example those working officially for his charity foundation, are known quite well and by name. How does the Groban fan become someone who knows and is known by him? How does one "get to know" or become a "friendly acquaintance" of such a person? There are at least seven ways in which this can happen. First, entries to pre-concert "Meet and Greets" (which happen at most concerts) can be obtained through several mechanisms: one is direct purchase (for about $\$ 500$ to $\$ 600$, concert ticket included), another is to win one from the fan club, a third is to purchase one to benefit various local area PBS stations, and a fourth is to win one offered by local radio stations. Knowing someone affiliated with the tour is 
another way that some have obtained these passes. A second opportunity to meet is to attend a charity event. Some of these events were sponsored by Groban's charity foundation and some were other charities that Groban was supporting, for example South Central Scholars in Los Angeles, Los Angeles County High School for the Arts, and the Prince's Trust in London. A third means to meet is to seek out the less organized meetings that happen before and after concerts and other events. Depending on factors like venue rules, weather, and how many fans were present, after about one third to half of his concerts Groban would come out to sign autographs. Fans would also wait at a venue for him to arrive and, if he had time, he would stop to say hello or perhaps sign an autograph. It should be noted that most often the fans waited with other fans. It was unusual to see a fan waiting alone. Attempting to meet Groban was a social occasion. A fourth way to meet one's hero is to work for charity: fans who were on the charity board or staff of Groban's charity foundation occasionally had a chance to speak with him, usually about charity business. A fifth means of contact was at CD signings at book and record stores. The sixth opportunity to approach was to attend television tapings for shows like Good Morning America, Kelly Ripa or Jimmy Kimmel. Groban often would linger during or after such tapings and sign a few autographs and/or say hello to some of the fans. These events were not limited to the United States; television appearances in the United Kingdom, France, Canada and other countries were frequent. In the United Kingdom where Groban was less known, it appeared quite easy to meet and speak with him before, during, or after a television appearance. A final means to arrange close contact with the celebrity was via personal interactions over media. While social media is still media and not face-to-face, the evolution of things like Twitter has meant that an individual fan can have a conversation or exchange with a celebrity like Groban who is on his own Twitter account and who frequently Tweets individual fans (Stever and Lawson 2013). Additionally Facebook and other forms of Internet question and answer sessions give the fan a chance to get an answer to his or her question. As an active Twitter account user, Groban has been observed to acknowledge some fans when he meets them in person by their Twitter handles, showing that he knows his acquaintances through this avenue of contact in addition to the face-toface ones.

A note should be made that clearly it is easier for a fan to get to know Groban if he or she has the financial means to support his charities. On the one hand, an argument could be made that Groban is just "marketing" himself and those who know him have purchased the opportunity. However, as in all social interactions, one's social and financial standing almost always dictates the people one has the opportunity to get to know. Is the relationship between high ranking members of the government and the constituents who know them any less valid or meaningful because it is the affluence of the constituent that has afforded him or her the opportunity to have the relationship in the first place? In the case of the fan and the celebrity, if the fan has the financial means to move in the same circles as the celebrity, of course he or she will get to know that celebrity better than the person who does not have the money to move in those circles. But controlling for the variable of socio-economic status, there were still numerous fans of ordinary means who gave evidence of knowing and being known by Groban. There were 
enough opportunities in this social situation to meet him without paying for the privilege to support the idea that such knowing and meeting is still very possible. Indeed, all of the cited cases above were individuals who were in an average middle income bracket. However, the social phenomenon being described in this paper is most often a characteristic of a middle income or better set of individuals with the means to attend concerts (with tickets ranging from $\$ 75$ to $\$ 600$ ), to travel to events, and to donate to charities.

The researcher participated in all of the kinds of events discussed. Encountering Groban was not difficult if one was willing to travel to various events. He appeared to be an open and friendly person who enjoyed meeting fans. At this stage (2016) of his career, with his level of success, he does not need to come out by his tour bus and sign 50 to 100 autographs. It would seem that he does it because he likes to do it. While it clearly could be "good business" to forge a connection with fans in this way, many successful artists do not bother.

Fans are often asked how they can afford to travel to concerts and other events, whether it be for the Groban fandom or for fandoms that have conventions (Star Trek). Here is one fan's answer to that question:

I am a single mom, I work full time hours in a very high stress job, I work mostly 12 hour night shifts, and I sleep when everyone else is awake. I do nothing for myself, ever. If Josh isn't touring, I take care of children [four], sleep when I can, and work a whole lot. Josh Groban shows are great because of Josh's talent, and his music is passionate and soothing ... it's a great stress relief. But, beyond that are all the friendships I make with people who have a similar passion ... the travel and fun. I'd never been on a plane before Groban! I'd never drive somewhere alone! Now I've been to Hollywood, New York, even London, England! It's definitely not because I have a lot of money, I don't shop, I don't have a fancy house, I don't own a lot of things but there's one thing I will do for myself, it's something that's worth it ... when Josh tours ... because it touches my soul!

\section{Characteristics of the artist}

Groban has been afforded a number of qualities that make him ideal for forging a connection with his fan base. Information in this area has been taken from numerous media interviews that he has given, with most of the stories he tells being told many times. In addition, he has been observed interacting with fans at all of the types of events listed above, including before and after at least seventyfive concerts.

Groban is a fan himself. He has felt a connection with media celebrities in his own lifetime, and so, in the words of several of the fans, "he gets it". From Björk to Paul Simon, from Céline Dion to Andrew Lloyd Weber, he has had the chance to meet many of his own favorites and even to work with some of them. This would appear to make him very sympathetic to the fan who holds him in such esteem and wants to meet him.

He has a remarkable memory. Indeed, he has only to see the same fan as few as three times on a tour when he has been known to say "Oh hello, it's nice to see you again". He also shows evidence of having an extremely high level of 
compassion for the varied and diverse fans he has, from very young children to very old grandmas and everyone in between. At one back stage meet and greet, an extremely elderly woman was there to have a picture taken with him. She had a walker and gave the appearance of being quite feeble. Security had Groban in a secured area and fans were to move to him to get their photo. Groban saw the woman struggling to come toward him and left his secured area to come to her saying "Please stay there... let me come to you!" He interacts this way with people in varying states of disability, with young children; from what has been observed, he is kind and patient with most people. This is not to say that being kind and patient is a condition for creating connections with fans. But it does not hurt.

Groban has created a safe environment for himself by hiring top notch security professionals. His tour manager and security chief have both been with him many years, the tour manager since his first tour in 2003, and the security chief since summer of 2007. They know the "regular" fans as well as Groban does. They also know who are the identified potential risks and watch for them with vigilance. If someone that is perceived as a potential threat is at an event, Groban just does not come out to meet anyone that night. This has been observed at a number of events throughout the years. Rules that govern fan behavior for group occasions are enforced and fans have learned (and quickly educate newcomers) that if the crowd is not well behaved, he will be whisked away on his bus. Groban's head of security prefaces any signing event by stating "the rules" and fans are happy to comply. At a recent event, a venue security person was overheard to say "What nice fans! That was really good..." referring to Groban stopping outside his bus to sign for several dozen fans after a concert on the 2015 Stages tour.

This situation where the fans are well behaved and venue security respectful has evolved after years of some not so nice situations, a few where fans were unruly, pushing and shoving and the signing was cut short. In a few other cases, particularly on the 2007 Awake tour, venue security was disrespectful and treated fans very badly. There were occasions where gathered fans were threatened by venue security with arrest if they did not disperse, and another common occurrence was that venue security would lie to fans who had gathered, either saying that he'd left already when it was clear he had not or simply stating that he was not coming out when eventually he actually did. After a few years, the venue security got better briefings by Groban's staff, and Groban's head of security became well known to the fans, establishing early on that he did not lie, and if he said the signing would not happen, it did not. If he came out and briefed the crowd, fans knew that Groban would be out to sign. Sometimes it was a long wait, but eventually a relationship of trust developed between Groban's personal security and the fans. Fans knew they would not be lied to or treated badly, and security knew the "regulars" and that they could be counted on to behave. The regulars would usually set the tone for the rest of the fans at any gathering and the after concert signings usually went very well. A norm was established that when the fan got a signature, protocol was that he or she would then move to the back to give others a chance, and that usually happened, in spite of crowds of fans being excited and anxious. 


\section{Discussion}

The symbolic interactionist perspective in sociology (Blumer 1969) talks about shared meanings in social settings. These shared meanings can be with respect to objects, words, or places. Within the social network of Groban, his fans, and his staff, symbols and meanings have evolved over Groban's career such that the social situations became somewhat predictable and thus both safer and more enjoyable. For example, in the absence of pushing and shoving during informal signings, everyone has a better time, no one gets hurt, and more people are able to have the chance to interact with Groban. Sometimes the interaction is brief and a one-time occurrence. Other times the fans who line up night after night are a core group of the same people who want to say hello again to their friend or, more often, friendly acquaintance. Groban's tour buses are the shared symbol for a place to gather; if one is to see Groban, this is the place it is most likely to happen. There are cues that indicate a signing is likely to take place, like the presence of small fences or moveable barriers, and the presence of the security person himself, waiting to share "the rules."

The media has depicted the fan interest in Groban as being characterized by "eros" or sexual attraction. While this is certainly true in many cases, what was observed more frequently could be more accurately characterized as "storge" (Greek): deep affection, such as that held for family members, students, patients (in the case of health care professionals, or others who are valued and esteemed, even if not known well enough to be actual friends. The fans most often exhibited affection and respect for Groban, and that affection and respect was reciprocated by him. In addition to this being observed, it could be inferred by the lengths Groban went to in order to ensure that he would be able to meet fans as safely and frequently as possible. On the night of a performance, why else would someone spend up to an hour "meeting and greeting" up to a hundred or more fans? While a few of these fans had paid for the encounter with their ticket, the much larger number of them had won or been given the opportunity in the ways described above. It was this affection that was observed either instead of or in addition to the romantic attraction more frequently depicted in fan-celebrity interactions, particularly those between male celebrities and female fans. The longer a fan was involved in the fan experience, the more likely it was that her interest was characterized by this deep affection and respect. As is often true in other kinds of real life attractions, what started out for the fan as a 'crush' would evolve over the years into a more stable and less intense kind of love, driven less by eros and more by storge.

Understanding the inner workings of a complex social network of any kind is almost impossible without getting some kind of insider insight. Part of the process of understanding this, or any, fandom is to get to know it, then come to appreciate, whatever the work is (that is, acting, singing, other artistic forms), the nature of the connections being formed. This researcher has worked hard to do this. Indeed, at an event (Turning Stone concert in Verona, NY, February 2007), she was asked (by a Groban insider with the tour) "Aren't you afraid of becoming what you study?" The answer to that question was "Of course not". This question reflects the presumption by some that being a fan, particularly a dedicated fan, is an undesirable thing. That presumption is based on faulty and flawed logic, as 
pointed out in Stever (2011a), which presented data supporting the idea that there are no more "celebrity worshippers" in organized fandom than there are in the public at large. Are there people who form troubling and sometimes delusional connections to media celebrities? Clearly there are. Are these people more likely than anyone else to be in organized fandom? Not only is that not the case from what has been observed, but organized fandom and connection with other fans has been observed to help fans have a more healthy perspective on their own interest, not a less healthy one. One young lady (age 19; Anonymous 1989) observed and interviewed on the Michael Jackson tour in 1989 shared:

I always thought that if I could meet Michael and we could just look into each other's eyes, he would know that I am "the one" for him. I held this fantasy for many months. Then that moment came and I did look into his eyes, and knew immediately that it wasn't real. It was just my own fantasy. From that point on I still loved Michael and went to many of his concerts, but I gave up my idea that we would be together. Seeing that there were other fans who felt the same way helped me understand this.

Numerous other examples of this kind of thing could be offered, describing the fan who, after experiencing catastrophic loss (most often of a romantic partner, although this has also been observed with the loss of a parent), finds solace in a connection with a favorite celebrity. This is a positive thing because often the fan is not ready for another "real" relationship. The connection felt with the celebrity compensates in a small way for the loss, and also helps the fan reconnect with the social world.

This discussion has not yet engaged the topic of the role of music in social life and in the healing properties it has for a troubled person. Schopenhauer (quoted in Sacks 2007: xi) said:

The inexpressible depth of music, so easy to understand and yet so inexplicable, is due to the fact that it reproduces all the emotions of our innermost being, but entirely without reality and remote from its pain. ... Music expresses only the quintessence of life and of its events, never these themselves.

While this topic could be an entire paper in itself, there is no doubt that one of the biggest aspects of Groban's appeal to his fans is the quality of his talent, the soothing nature of his voice that affords a sense of emotional connection, all connected to the way that humans respond to music as a unique form of communication. One cannot separate out the attraction fans feel to "Groban the musician" from "Groban the human being". It's all one package and part of what makes it possible for a fan to forge a friendly acquaintanceship with someone they know principally through media. One fan recounted: "There's no one like him that reaches your soul and tugs the heart strings..."

This connection and type of relationship, far from being an anomaly, is extremely common in this fandom and has been observed in other fandoms (for example, Star Trek) as well. Further work is needed to better understand the 
relationships that musicians, in particular, and celebrities, in general, develop with their fans.

\section{Endnotes}

1 "Aca-fan" is a term from media fan studies meaning "an academic who usually teaches in cultural studies, studies fandom, supports the cultural legitimacy of fandom as a social identity and proudly attests to being a fan in his / her own life and work" (Duffett 2013: 289). They are not simply scholars who also have fan passions, but rather fans who use their academic role to support the wider acceptance of fandom.

\section{References}

\section{Bibliography}

Atkinson, P. and Hammersley, M. 1994. Ethnography and Participant

Observation. In N. K. Denzin and Y. S. Lincoln Eds. Handbook of Qualitative Research. Thousand Oaks, CA: Sage: 248-261.

Bennett, L. 2014. Fan/Celebrity Interactions and Social Media: Connectivity and Engagement in Lady Gaga Fandom. In L. Duits, K. Zwaan and S. Reijnders Eds. The Ashgate Research Companion to Fan Cultures. Farnham: Ashgate: 109120.

Blumer, H. 1969. Symbolic Interactionism: Perspective and Method. Englewood Cliffs, NJ: Prentice-Hall.

Cavicchi, D. 1998. Tramps Like Us: Music and Meaning Among Springsteen Fans. New York: Oxford University Press.

Charmaz, K. 2008. Grounded Theory as an Emergent Method. In S.N. Hesse-Biber and P. Leavy Eds. Handbook of Emergent Methods. New York: The Guilford Press: $155-172$.

Click, M. et al. 2013. Making Monsters: Lady Gaga, Fan Identification, and Social Media. Popular Music and Society 36 (3): 360-379. http://dx.doi.org/10.1080/03007766.2013.798546

Des Barres, P. and Navarro, D. 2005. I'm with the Band: Confessions of a Groupie. Chicago: Review Press.

Dilling-Hansen, L. 2015. Affective Fan Experiences of Lady Gaga. Transformative Works and Cultures 20. http://dx.doi.org/10.3983/twc.2015.0662

Duffett, M. 2013. Understanding Fandom: An Introduction to the Study of Media Fan Culture. New York: Bloomsbury.

2014. Celebrity: The Return of the Repressed in Fan Studies? In L. Duits, K. Zwaan and S. Reijnders Eds. The Ashgate Research Companion to Fan Cultures. Farnham: Ashgate: 163-180.

Ferris, K. O. -

2001. Through a Glass, Darkly: The Dynamics of Fan-Celebrity Encounters. Symbolic Interaction 24 (1): 25-47.

http://dx.doi.org/ 10.1525/si.2001.24.1.25 
2004. Seeing and Being Seen: The Moral Order of Celebrity Sightings. Journal of Contemporary Ethnography 33 (3): 236-264. http://dx.doi.org/10.1177/0891241604263585

2005. Threat Management: Moral and Actual Entrepreneurship in the Control of Celebrity Stalking. In S. Burns Ed. Ethnographies of Law and Social Control. New York: JAI/Elsevier Science Press: 9-29.

Giles, D. 2010. Psychology of the Media. New York: Palgrave Macmillan.

Hartmann, T. and Goldhoorn, C. 2011. Horton and Wohl Revisited: Exploring

Viewer's Experience of Parasocial Interaction. Journal of Communication, 61 (6): 1104-1121.

http://dx.doi.org/ 10.1111/j.1460-2466.2011.01595.x

Horton, D. and Wohl, R. 1956. Mass Communication and Para-social Interaction: Observations on Intimacy at a Distance. Psychiatry 19 (3): 215-230. http://dx.doi.org/10.1521/00332747.1956.11023049

Jenkins, H. 1992. Textual Poachers: Television Fans and Participatory Culture. London and New York: Routledge.

Kelliher, F. 2005. Interpretivism and the Pursuit of Research Legitimisation: An Integrated Approach to Single Case Design. The Electronic Journal of Business Research Methodology 3 (2): 123-132.

http://www.ejbrm.com/issue/download.html?idArticle=156; Accessed: 25 September 2016.

Klimmt, C. et al. 2006. Parasocial Interactions and Relationships. In Bryant, J. and Vorderer, P. Eds. Psychology of Entertainment. London and New York: Routledge: 291-313.

Leets, L. et al. 1995. Fans Exploring Expressed Motivations for Contacting Celebrities. Journal of Language and Social Psychology 14 (1-2): 102-123. http://dx.doi.org/10.1177/0261927X95141006

Maltby, J. et al. 2006. Extreme Celebrity Worship, Fantasy Proneness and

Dissociation: Developing the Measurement and Understanding of Celebrity Worship Within a Clinical Personality Context. Personality and Individual Differences 40 (2): 273-283.

http://dx.doi.org/10.1016/j.paid.2005.07.004

McCutcheon, L. E. et al. -

2003. A Cognitive Profile of Individuals Who Tend to Worship Celebrities. Journal of Psychology 137 (4): 309-322. http://dx.doi.org/10.1080/00223980309600616

2016. Further Validation of an Indirect Measure of Celebrity Stalking. Journal of Studies in Social Sciences 14 (1): 75-91.

http://infinitypress.info/index.php/jsss/article/view/1268

Merriam-Webster 2004. Merriam-Webster's Collegiate Dictionary. Springfield, MA: Merriam-Webster.

Mittell, J. 2006. Narrative Complexity in Contemporary American Television. The Velvet Light Trap 58 (1): 29-40.

Reijnders, S. et al. 2014. Close Encounters: Ritualizing Proximity in the Age of Celebrity: An Ethnographic Analysis of Meet-and-Greets with Dutch Singer Marco Borsato. European Journal of Cultural Studies 17 (2): 149-169. http://dx.doi.org/10.1177/1367549413508098 
Rubin, R. B. and McHugh, M. P. 1987. Development of Parasocial Interaction Relationships. Journal of Broadcasting and Electronic Media 31 (3): 279-292. http://dx.doi.org/10.1080/08838158709386664

Sacks, O. 2010. Musicophilia: Tales of Music and the Brain. Toronto: Vintage Canada.

Stever, G.S. -

2008. The Celebrity Appeal Questionnaire: Sex, Entertainment or Leadership. Psychological Reports 103 (1): 113-120. http://dx.doi.org/10.2466/pr0.103.1.113-120

2009a. Fan/Celebrity Symbiotic Social Relationships: A Participant-Observer Ethnography of Fan Clubs. International Communications Association: Theme: Keywords in Communication, Chicago, IL, May 22-26, 2009. 2009b. Parasocial and Social Interaction with Celebrities: Classification of Media Fans. Journal of Media Psychology 14 (3): 1-39.

2011a. Celebrity Worship: Critiquing a Construct. Journal of Applied Social Psychology 41 (6): 1356-1370. http://dx.doi.org/10.1111/j.1559-1816.2011.00765.x

2011b. Fan Behavior and Lifespan Development Theory: Explaining Para-social and Social Attachment to Celebrities. Journal of Adult Development 18 (1): $1-7$. http://dx.doi.org/10.1007/s10804-010-9100-0

2011c. 1989 vs. 2009: A Comparative Analysis of Music Superstars Michael Jackson and Josh Groban, and Their Fans. Journal of Media Psychology 16 (1): 1-30.

2013. Mediated vs. Parasocial Relationships: An Attachment Perspective. Journal of Media Psychology 17 (3): 1-31.

2016. Evolutionary Theory and Reactions to Mass Media: Understanding Parasocial Attachment. Psychology of Popular Media Culture, advance online publication. http://dx.doi.org/10.1037/ppm0000116

Stever, G. S., and Lawson, K. 2013. Twitter as a Way for Celebrities To Communicate With Fans: Implications for the Study of Parasocial Interaction. North American Journal of Psychology 15 (2): 339-354.

Thorne, S. 2011. An Exploratory Investigation of the Theorized Levels of Consumer Fanaticism. Qualitative Market Research: An International Journal 14 (2): 160-173. http://dx.doi.org/10.1108/13522751111120675

Willis, P. and Trondman, M. 2000. Manifesto for Ethnography. Ethnography 1 (1), $5-16$. http://dx.doi.org/10.1177/14661380022230679

Zubernis, L. and Larsen, K. 2012. Fandom at the Crossroads: Celebration, Shame and Fan/Producer Relationships. Newcastle upon Tyne: Cambridge Scholars Publishing. 


\section{Interview}

Anonymous [19-year-old female]. 1989. Interview with Gayle Stever, Los Angeles, CA, January.

\section{Videography}

CBC Canada 2003. Interview on the Bed, 18 February, CBC Canada.

ET Canada Global TV 2015. Entertainment Tonight Canada EPS (2513), 10 June, EPS Shaw Media.

VH1 2003. Cribs, 26 November, MTV Productions. 